\title{
On the Retrieval of Significant Wave Heights from Spaceborne Synthetic Aperture Radar (ERS-SAR) using the Max-Planck Institut (MPI) Algorithm
}

\author{
NELSON VIOLANTE-CARVALHO \\ Southampton Oceanography Centre, University of Southampton, European Way \\ Southampton SO14 3ZH, UK \\ Manuscript received on August 11, 2004; accepted for publication on June 16, 2005; \\ presented by ALCIDES N. SIAL
}

\begin{abstract}
Synthetic Aperture Radar (SAR) onboard satellites is the only source of directional wave spectra with continuous and global coverage. Millions of SAR Wave Mode (SWM) imagettes have been acquired since the launch in the early 1990's of the first European Remote Sensing Satellite ERS-1 and its successors ERS-2 and ENVISAT, which has opened up many possibilities specially for wave data assimilation purposes. The main aim of data assimilation is to improve the forecasting introducing available observations into the modeling procedures in order to minimize the differences between model estimates and measurements. However there are limitations in the retrieval of the directional spectrum from SAR images due to nonlinearities in the mapping mechanism. The Max-Planck Institut (MPI) scheme, the first proposed and most widely used algorithm to retrieve directional wave spectra from SAR images, is employed to compare significant wave heights retrieved from ERS-1 SAR against buoy measurements and against the WAM wave model. It is shown that for periods shorter than 12 seconds the WAM model performs better than the MPI, despite the fact that the model is used as first guess to the MPI method, that is the retrieval is deteriorating the first guess. For periods longer than 12 seconds, the part of the spectrum that is directly measured by SAR, the performance of the MPI scheme is at least as good as the WAM model.
\end{abstract}

Key words: wind waves, Synthetic Aperture Radar (ERS-SAR), Max-Planck Institut (MPI) Algorithm, Campos Basin, WAM wave model, heave-pitch-roll buoy measurements.

\section{INTRODUCTION}

With the advent of Synthetic Aperture Radar (SAR) measurements and with the better understanding of the imaging processes, retrieval algorithms have been proposed and the full directional spectra extracted from SAR images are now available in

Present address: Departamento de Oceanografia Universidade do Estado do Rio de Janeiro/UERJ

Rua São Francisco Xavier, 524

20550-013 Rio de Janeiro, RJ, Brasil

E-mail: violante_carvalho@yahoo.co.uk quasi-real time with global coverage. Several meteorological centers are investigating methods on how to use the new information retrieved from spaceborne SAR measurements in order to improve the wave forecasting. It is recognized that the assimilation of wave observations can improve both the present sea state and, in the case of swell, the forecast of the models (see for example Lionello et al. 1995, Voorrips et al. 1997, Breivik et al. 1998, Dunlap et al. 1998). Data assimilation methods 
have been used for over four decades in meteorological models with the objective of improving the forecasts by making use of the widely available network of meteo-stations all over the world. Wave modelers, in contrast, have put off such an approach mainly due to the sparseness of wave observations. However after the advent of satellite oceanography this picture has changed and, in the particular case of wind waves, since the 1990's measurements of significant wave heights from altimeters became available and have been assimilated by several weather centers.

There are two main limitations in the images observed by SAR which demands great care in the process to derive the wave spectrum. In the first place there is a $180^{\circ}$ directional ambiguity inherent in frozen images. In addition the SAR imaging mechanism is strongly nonlinear due to distortions induced by the orbital wave motions (the velocity bunching mechanism) causing degradation of the azimuthal (parallel to the satellite flight) resolution. The result is that there is a loss of information beyond a cut-off wavenumber and waves with wavelengths shorter than 150-200 $\mathrm{m}$ propagating in the azimuthal direction are not mapped onto the SAR image directly.

The extraction of the wave spectrum from a SAR image spectrum requires additional information to solve the directional ambiguity and to recover the spectral information at the higher wavenumber band corresponding in general to the wind sea part of the spectrum. This problem has been tackled by three different methods for which the basic difference in their strategies lies in how they address the problem of reconstructing the directional spectrum beyond the high wavenumber azimuthal cut-off.

The first retrieval algorithm was developed at the Max-Planck Institut (MPI) by Hasselmann and Hasselmann (1991) and an improved version was published later by Hasselmann et al. (1996). They derived a closed expression for the mapping of a wave spectrum onto a SAR image spectrum, the forward mapping relation, together with a compu- tationally efficient technique to invert the mapping relation. The main idea behind the MPI scheme is to use a first guess wave spectrum, in general from a wave model, and iteratively change its inverted SAR image spectrum to match the observed SAR image spectrum. More details about the MPI scheme and a revision of the main features of the SAR ocean wave imaging mechanisms is presented in Violante-Carvalho and Robinson (2004) and in Violante-Carvalho et al. (2005). The second retrieval scheme to be proposed is a simplified version of the MPI scheme. Krogstad et al. (1994) applied a very similar approach but they use a quasilinear approximation of Hasselmann and Hasselmann's full nonlinear forward mapping relation. Ignoring the nonlinearities applying a quasi-linear approximation might cause spurious swell peaks when the SAR image spectrum is mapped back into the wave spectrum (see Hasselmann et al. 1985). The Semi-Parametric Retrieval Algorithm (SPRA), the third retrieval scheme, was proposed by Mastenbroek and de Valk (2000) who employ additionally the wind information from the scatterometer that is operating simultaneously with the SAR. In this approach there is no need for a first guess wave spectrum since they apply a parameterized wind sea spectrum and estimate its direction of propagation from the wind measurements. The drawback of this methodology is that the direction of propagation of swell is not determined and in general there is a spectral gap in the vicinity of the azimuthal cut-off, the delimitation between the part of the spectrum observed and not observed by SAR.

The quality of the retrieval schemes compared against independent directional data has not yet been demonstrated. Bauer and Heimbach (1999) compared the significant wave height extracted from ERS-1 SAR using the MPI scheme against Topex altimeter data founding good correlation between both measurements. The spectral performance of the MPI scheme was compared against three years of WAM wave model spectra (Heimbach et al. 1998) which were used themselves as first 
guess for the inversion. Although the overall agreement was quite promising it was clear that an assessment against independent data, for example spectra from a directional buoy, would be more likely to point to any deficiencies of the method. More recently Voorrips et al. (2001) compared the MPI and the SPRA schemes against several non directional buoys deployed mostly off the North American coast. In that work it became clear that both schemes have room for improvement, and that their main deficiencies lie in how to augment the spectral information beyond the azimuthal cut-off.

The MPI scheme runs operationally at the European Centre for Medium-Range Weather Forecasts (ECMWF) and is the most broadly used algorithm to date implemented in several institutions around the world. However very little is known about its performance assessed against independent measurements. The main goal of the present work is to supply a detailed investigation of the possibilities/limitations of retrieving significant wave height (SWH) with a spaceborne SAR instrument using the MPI retrieval algorithm. We are comparing SWH extracted from SWM imagettes using the improved MPI scheme (Hasselmann et al. 1996) against directional buoy spectra measured in the open ocean in the South Atlantic and against WAM spectra used as first guess to the inversion.

\section{DATA SET}

\subsection{Buoy Measurements}

Campos Basin, off Rio de Janeiro (Figure 1), is the most important oil and gas basin in Brazil. More than $70 \%$ of the petroleum prospected in the country comes from the tens of platforms located in this area. Every day several offshore operations take place in the region, which operatively depend on the sea state, in particular on the surface waves. This is one of the most important regions in Brazil with huge urban concentrations and strong commercial, industrial and touristic activities.

The South Atlantic Deep Water Program (PROCAP) was an extensive experiment carried out by the Brazilian Oil Company PETROBRAS in Campos Basin to study the main oceanographic features of the region. In terms of wind and wave measurements a heave-pitch-roll buoy was moored in a depth over 1000 meters at position $22^{\circ} 31^{\prime} \mathrm{S}$ and 39 58 ${ }^{\prime} \mathrm{W}$ from March 1991 to March 1993 and from January 1994 to July 1995. For the analysis presented in this work, one year of buoy measurements is employed comprising the period from May, 1994 to April, 1995. The wind speed and direction were measured hourly from the buoy by two Young propeller-vane anemometers at a height of $3.78 \mathrm{~m}$ and $4.43 \mathrm{~m}$ and later converted for the standard height of $10 \mathrm{~m}$. Each measurement is the average of a ten minute record, obtained one per hour.

The wave buoy acquired three time series, the vertical displacement $(\eta)$ and two slopes $\left(\eta_{x}\right.$ and $\left.\eta_{y}\right)$ in the east and north directions, respectively. These time series are the starting point for the spectral analysis performed. The displacements were sampled at a rate of $1 \mathrm{~Hz}$ during 20 minutes eight times a day every three hours. The spectral estimators were obtained using the Welch Method. Records consisting of 1024 data points (with a sample length of approximately 17 minutes) were segmented in 16 partitions of 64 points yielding 32 degrees of freedom and frequency resolution of $0.015625 \mathrm{~Hz}$. A fast Fourier transform (FFT) was applied to all three time series employing a Hanning window and 50\% overlap between adjacent segments. See Violante-Carvalho et al. (2004) for more details about the buoy data processing.

\subsection{WaVe Model Data}

The directional ocean wave spectra are computed using the workstation version of the model WAM cycle 4 . The spectra are computed every 6 hours on a latitude-longitude grid with a spatial resolution of $1^{\circ}$ covering the whole South Atlantic basin from the Equator line to $72^{\circ} \mathrm{S}$ and from $74^{\circ} \mathrm{W}$ to $30^{\circ} \mathrm{E}$, which totals 7488 grid points. Both the source and the advection terms have a time step of 20 minutes for all the 600 spectral components ( 25 frequencies and 24 


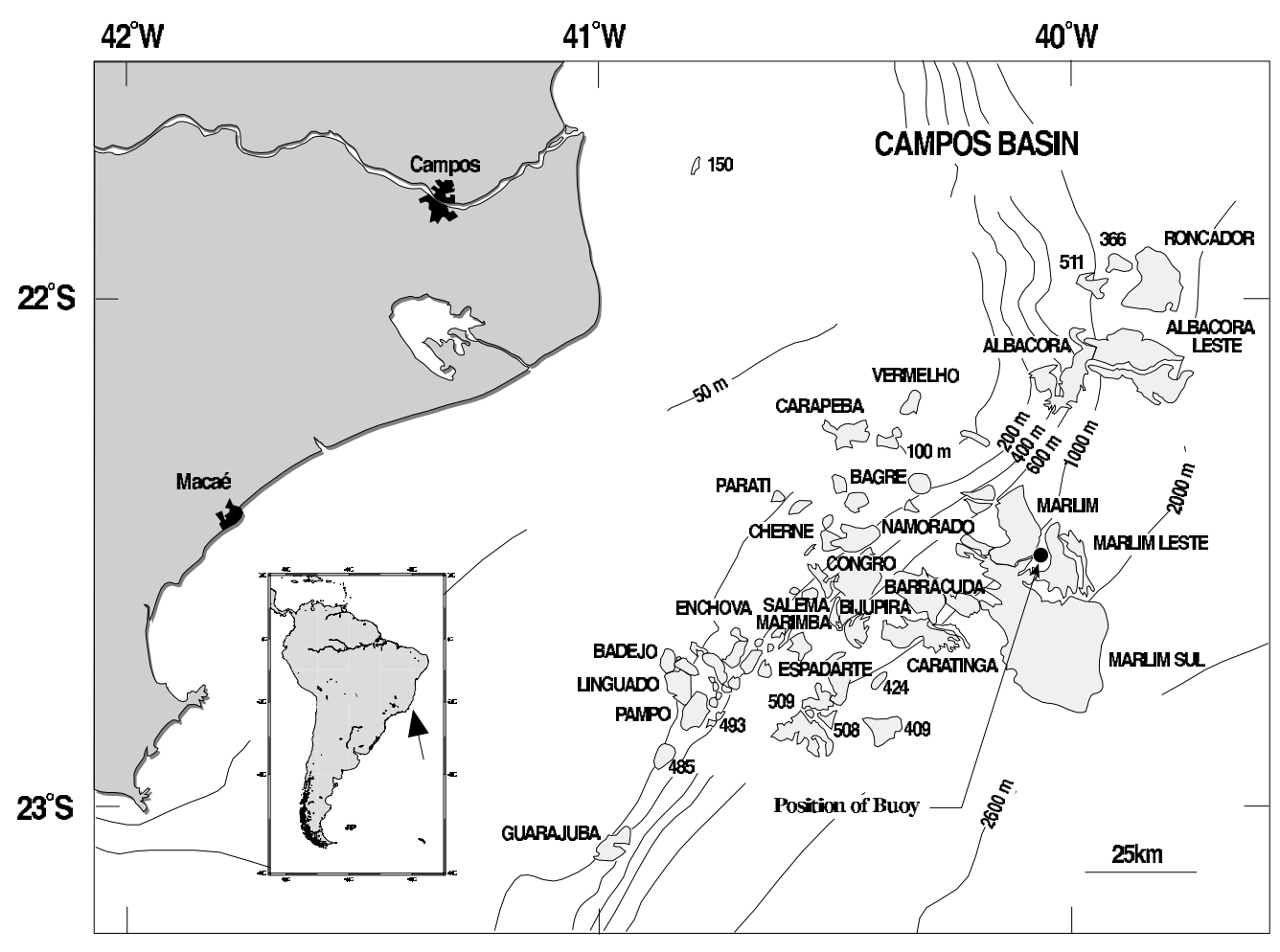

Fig. 1 - The position of the buoy in Campos Basin, Brazil. The oil fields are represented by the shaded areas.

directions). More detailed information of the main characteristics of the third generation WAM model is described in WAMDI Group (1988), Günther et al. (1992), Komen et al. (1994).

\subsection{WIND INPUT}

The wind input is from the Atmospheric General Circulation Model (AGCM) which is run operationally by the European Centre for MediumRange Weather Forecasts. Two different data sets were obtained from the British Atmospheric Data Centre (BADC): the ECMWF Re-Analysis (ERA) from 1991 to February 1994 and the ECMWF Operational Analysis (from March 1994 to December 1995). Both data sets have variable altitude resolution divided in 31 levels with maximum altitude of $30 \mathrm{~km}$, a latitude-longitude resolution of $1.125^{\circ}$ and the wind field is computed every 6 hours. The wind field at 10 meters height $\left(u_{10}\right)$ is used to drive the wave model.

\subsection{Collocated Data}

The extraction of the two dimensional wave spectral information from SAR images is not a trivial task. The nonlinearity of the imaging mechanism due to Doppler shifts induced by the long-wave orbital motions (velocity bunching mechanism) results in image smearing and loss of information beyond the so-called azimuthal cut-off wave number. In addition, satellite SAR images suffer from a $180^{\circ}$ frozenimage ambiguity. So any algorithm to retrieve the wave spectral information from SAR spectra must overcome such limitations. The MPI scheme developed by Hasselmann and Hasselmann (1991) removes the $180^{\circ}$ ambiguity and augments the wave spectral information beyond the azimuthal cut-off wave number using a first-guess wave spectrum from a model.

A data set was constructed which matches the SAR spectra with the corresponding data from the 
wave buoy. The collocation criteria applied are that all SAR image spectra were collocated in space and time with WAM spectra at a maximum distance of $50 \mathrm{~km}$ and maximum time separation of 30 minutes. For the comparison between retrieved wave spectra and buoy measurements we have chosen a maximum time difference of 1.5 hour and a maximum distance of $150 \mathrm{~km}$, yielding a total of 105 matched spectra. We have chosen these collocation criteria due to the relative temporal invariance and spatial homogeneity expected to be encountered in deep ocean areas. In relation to the satellite track both paths were equally selected, with $49 \%$ of the cases consisting of descending orbit and $51 \%$ ascending.

\section{MATERIALS AND METHODS}

Two different methods are employed for the validation of the SWH retrieved from ERS-SAR using the MPI scheme. In the first approach different wave systems of different spectra are cross assigned $(\mathrm{SAR} \times$ Buoy and WAM $\times$ Buoy). The partitioning scheme presented in Hasselmann et al. (1996) is used for the extraction of the wave systems of the directional spectrum, each one of them represented by mean parameters, such as SWH, direction of propagation and mean wave length. The partitioning yields up to four classes of wave systems based on the wave age, that is wind sea, swell, old wind sea and mixed wind sea and swell.

Each partitioning is considered to be an independent wave system generated by a different meteorological event, therefore some criteria are employed for the correct cross assignment of wave systems of different spectra. The first criterion is that the coordinates in $\mathbf{k}$ space of two wave systems must be less than some arbitrary value, reading

$$
\frac{\left(k_{x}^{a}-k_{x}^{b}\right)^{2}+\left(k_{y}^{a}-k_{y}^{b}\right)^{2}}{\left(k_{x}^{a 2}+k_{x}^{b 2}\right)+\left(k_{y}^{a 2}+k_{y}^{b 2}\right)} \leq 0.75
$$

where $\left(k_{x}^{a}, k_{y}^{a}\right)$ is the wave number of a wave system of spectrum A and $\left(k_{x}^{b}, k_{y}^{b}\right)$ is its counterpart in spectrum B. Another criterion is employed based on the wave age. Different wave systems are cross assigned if they are of the same type, that is both are for example wind sea or both are swell. In this work old wind sea and mixed wind sea and swell are not taken into account. The third criterion is an energy threshold limit to eliminate spurious peaks. The partitions must be above a minimum level

$$
e_{\min }=\frac{20 \cdot 10^{-6}}{f_{p}^{4}+3 \cdot 10^{-3}}
$$

where $f_{p}$ is the peak frequency. The last and fourth criterion is that in case of more than one partition fulfills the above conditions the closest one in $\mathbf{k}$ space is chosen.

The total energy of a wave system $\left(E_{t}\right)$ can be determined integrating over the spectral interval that it belongs to and therefore the SWH of a wave system is

$$
4 \sqrt{E_{t}}=4\left\{\int S(f, \theta) d f d \theta\right\}^{1 / 2} .
$$

The main difficulty in the procedure for the cross assignment is the right selection of a wave system and its counterpart in another spectrum, for instance to intercompare the wind sea from the buoy against the wind sea from SAR or the model. Although the criteria listed above seem to be rigorous enough to assure the correct cross assignment, the procedure may select nonassociated wave systems. For that reason a second method for the validation of the SWH retrieved from the MPI scheme is also employed. Rather than the two dimensional directional spectrum, $S(f, \theta)$, the one dimensional frequency spectrum, $S(f)$, is used for the evaluation of the performance of the retrieval scheme. In this approach the directional spectra retrieved from SAR and estimated by the WAM are integrated yielding the frequency spectra whereas the first Fourier components, and therefore $S(f)$, are directly measured by the buoy. The comparisons are performed over frequency bands, where the SWH over a frequency band is

$$
4 \sqrt{e_{t}}=4\left\{\int_{f_{\min }}^{f_{\max }} S(f) d f\right\}^{1 / 2}
$$


where $e_{t}$ is the total energy over the frequency band interval and $f_{\max }$ and $f_{\min }$ are the limits of the interval.

Although the intercomparison of spectra over specific frequency bands seems to be the most rigorous option, both approaches discussed earlier will be presented in this work. The use of wave systems extracted with the partitioning scheme is the most feasible solution for assimilation purposes (Hasselmann et al. 1997, Dunlap et al. 1998, Heimbach et al. 1998), despite the fact that there is a degree of uncertainty in the cross assignment of different wave systems. However the partitioning scheme has a very desirable feature that suits very well for wave data assimilation purposes, that is, each wave system is defined by a number of mean parameters therefore reducing the number of degrees of freedom of the spectrum. Using both approaches for the comparison is a good opportunity to investigate the assignment criteria that needs to be applied in wave assimilation procedures. Being too rigorous in the cross assignment will imply in unnecessarily reducing the number of matches, therefore the best criteria for the cross assignment needs to be investigated with this compromise in mind.

\section{RESUlts}

The scatter plots of SAR $\times$ Buoy and WAM $\times$ Buoy are shown in Figure 2 where SWH is calculated over the whole frequency domain, reading

$$
H_{S_{t}}=4\left\{\int S(f) d f\right\}^{1 / 2} .
$$

It is clear that the performance of the WAM wave model is superior than the MPI scheme retrievals, even though the MPI scheme uses the WAM spectrum as first guess. The mean value of $\mathrm{SWH}$ from the MPI scheme is $9.6 \%$ higher than the one estimated by the WAM, whereas the scatter in the WAM is approximately $25 \%$ lower than the scatter in the SAR retrievals. Therefore the MPI retrieval scheme deteriorates the first guess used to the inversion when one considers the whole frequency domain.
Due to the Doppler effect of moving targets there is an azimuthal displacement in the imaging process caused by the orbital motions of the waves. As a consequence waves shorter than about $200 \mathrm{~m}$ are not mapped directly onto SAR images and therefore there is a high wavenumber cut-off beyond which there is no information. To augment the spectrum beyond this cut-off and to resolve the directional ambiguity of frozen images a first guess from a wave model is employed in the MPI algorithm. In order to investigate the performance of the MPI scheme in the low wavenumber band directly measured by SAR, the SWH of the wave components longer than $225 \mathrm{~m}$ (or periods greater than 12 seconds) is calculated using

$$
H_{S_{12}}=4\left\{\int_{f_{1}}^{f_{2}} S(f) d f\right\}^{1 / 2}
$$

for $f_{1}=0$ and $f_{2}=1 / 12 \mathrm{~Hz}$. The scatter plots are shown in Figure 3, where in contrast to the results in Figure 2 the performance of the MPI scheme in the frequency band directly measured by SAR is as good as the WAM model. The WAM results are virtually bias free whereas the SAR retrieved values have a positive bias, however the MPI scheme presents standard deviation and normalized RMS error of the same order as WAM.

Figure 4 shows the scatter plots of SWH of the cross assigned partitions using (1). The statistics shown in Figure 4 are very similar to those in Figure 2 which is an indication that the criteria for the cross assignment is selecting only related partitions. The reason why the number of partitions in Figure 4 differ among plots (and are different from the number of spectra in Figure 2 and 3) is that more than one partition may be selected in the same spectrum.

The SWH computed over specific frequency bands using (2) is shown in Figure 5 where the statistics present in more spectral detail the comparison of the energy retrieved with the MPI scheme and estimated by WAM against buoy measurements. The WAM results are virtually bias free over the whole spectral domain whereas the SAR retrievals show a positive bias, which confirms that the MPI scheme is 

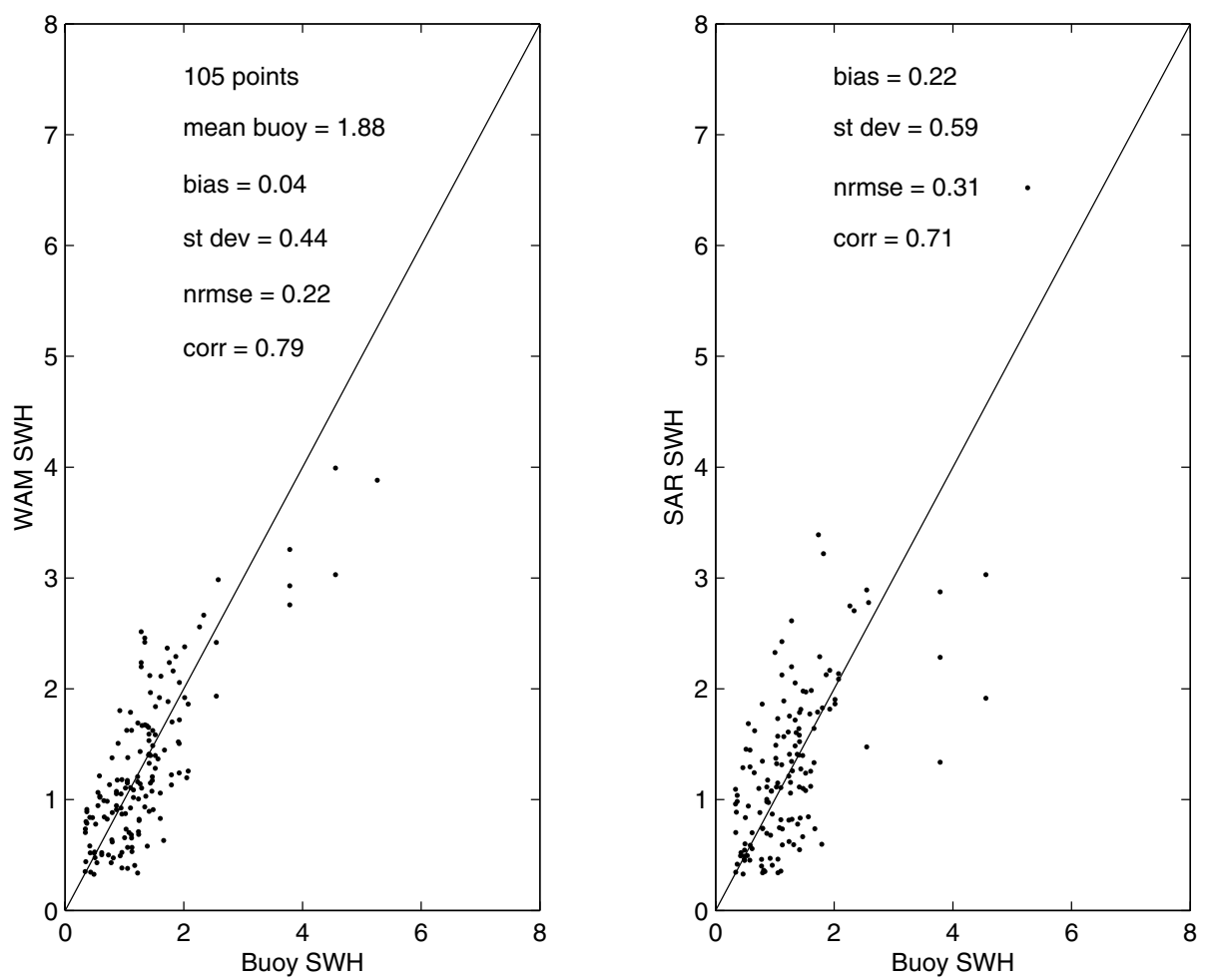

Fig. 2 - Scatter plots of Significant Wave Height (SWH) calculated using (3). On the left plot SWH computed by the WAM model against buoy measurements and on the right plot SWH retrieved from SAR against buoy measurements (the line of unity slope is also shown). The statistics represent, respectively, bias, standard deviation (st dev), RMS error normalized with the RMS buoy wave height (nrmse) and correlation (corr).

adding its own error and hence increasing the bias. However in the spectral band with periods greater than 12 seconds, the bias of the SAR data decreases gradually and for the frequency band with periods longer than 16 seconds it has a smaller bias than the WAM estimates. The standard deviation and normalized root mean square (RMS) error of SAR retrievals and WAM estimates show the same trend to increase with period. For shorter waves with periods smaller than 12 seconds the MPI scheme presents greater errors. For longer waves, on the other hand, the error of the MPI scheme is of the same order as the WAM estimates and, for some frequency bands, even smaller.

\section{DISCUSSION}

One year of buoy measurements acquired in deep waters is employed for the assessment of Significant Wave Height (SWH) retrieved using the MaxPlanck Institut algorithm and estimated by the WAM wave model. Two different methods were employed in the analysis. Firstly, wave systems, each one a constituent of the directional spectrum, are selected and cross assigned using a partitioning scheme. The investigation of the cross assignment of wave systems is of interest for wave data assimilation studies for reducing the amount of data being interpolated. On the second approach the two dimensional directional spectra retrieved from SAR 

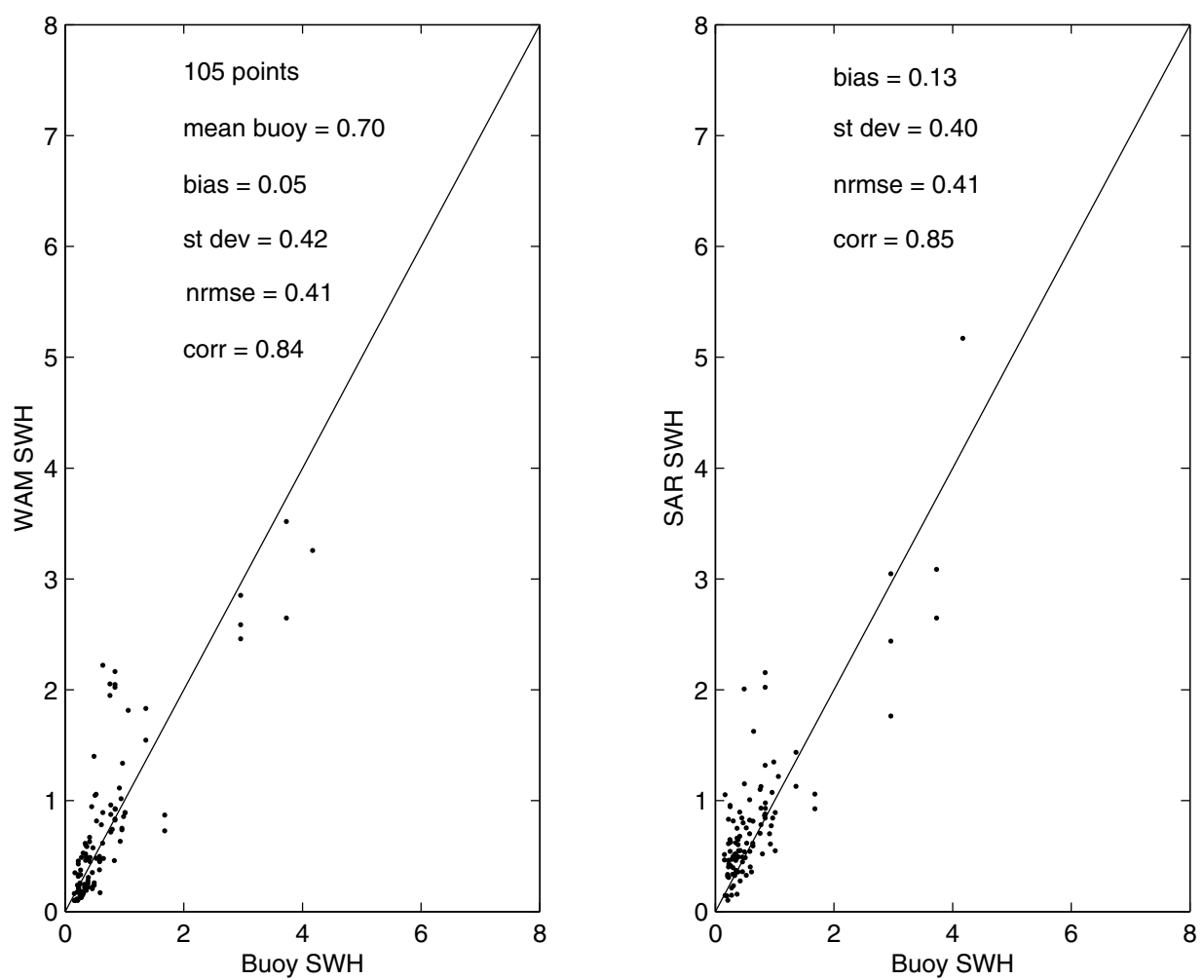

Fig. 3 - Same as Figure 2 but for values of $H_{S_{12}}$ (4).

and estimated by the WAM are integrated yielding the one dimensional frequency spectrum. The assessment is performed over frequency bands which guarantees that only related information is being compared. In both approaches the statistics are very similar which is indicative that the criteria employed for the cross assignment are good enough.

Heimbach et al. (1998) comparing WAM estimates against SAR retrievals that used the wave model results themself as first guess have found a systematic underprediction of the energy of the swell components and an overprediction of the wind sea, whereas from measurements presented in this work this trend was not observed with the model being virtually bias free over the whole spectral range. Confirming the findings of Voorrips et al. (2001), the MPI scheme in fact deteriorates the values of SWH used as first guess for the inversion adding its own error with the scatter in the WAM-Buoy compar- isons being $25 \%$ lower than the SAR-Buoy scatter. In accordance to the results presented by Dunlap et al. (1998), the mean value of SWH retrieved using the MPI algorithm is about $10 \%$ higher than the mean value of SWH computed by the WAM. However, in disagreement with Voorrips et al. (2001), the performance of the MPI scheme is shown to be as good as (or in some frequency bands even somewhat better) than the wave model for values of SWH computed considering only the low wavenumber part of the spectrum directly measured by SAR - waves longer than $225 \mathrm{~m}$.

Therefore, as demonstrated in this work, the assimilation of the directional spectra retrieved from SAR images using the MPI scheme must be performed with great care. Although in fact the retrieval algorithm performs at least as good as the WAM wave model for the extraction of the SWH in the low wavenumber part of the spectrum (the 

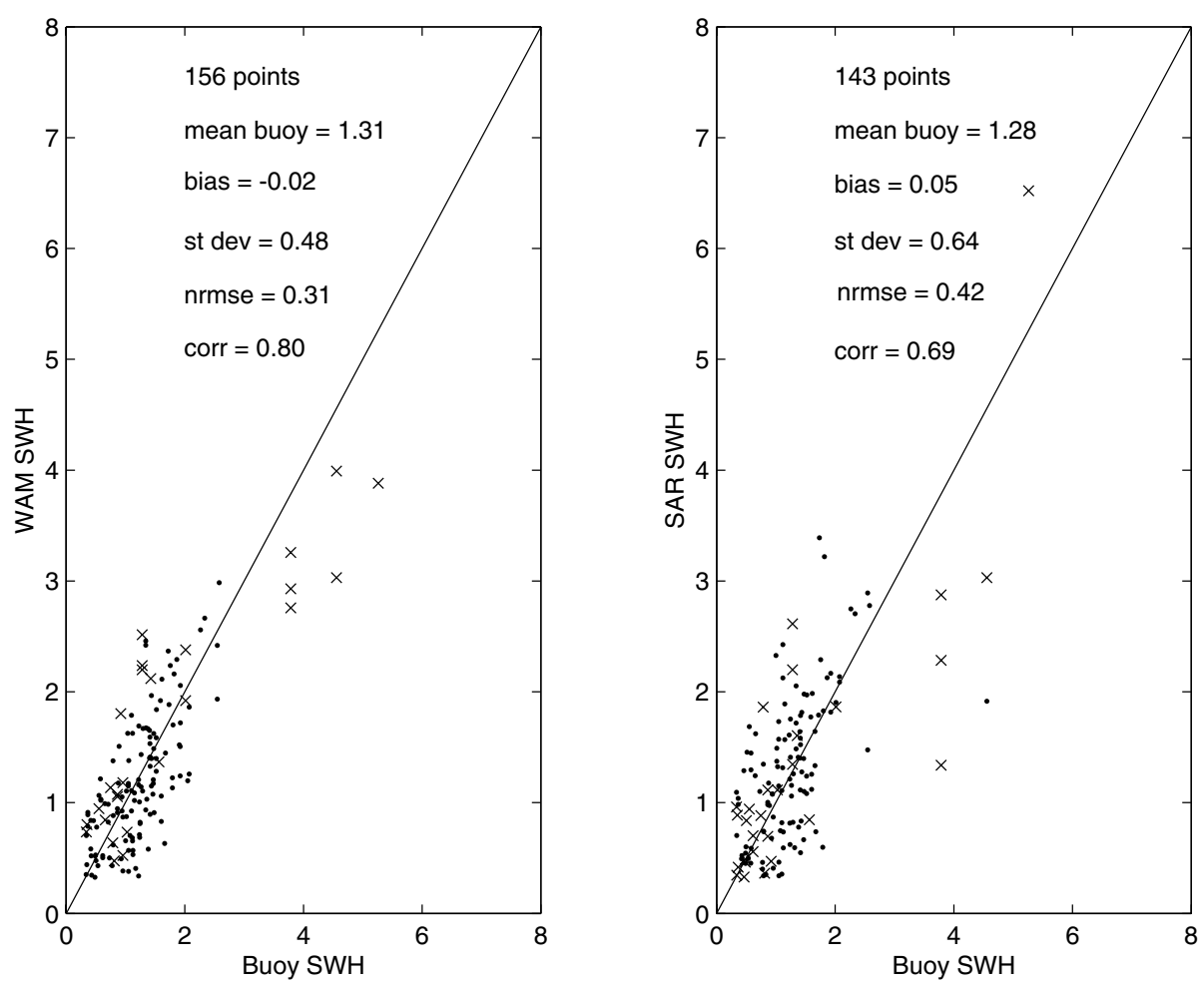

Fig. 4 - Scatter plots of SWH for every partition calculated using (1). On the left plot SWH computed by the WAM model against buoy measurements and on the right plot SWH retrieved from SAR against buoy measurements (the crosses are the partitions whose mean wavelength are greater than $225 \mathrm{~m}$ - periods greater than $12 \mathrm{~s}$ ). Statistics as in Figure 2 with the line of unity slope drawn passing through the origin.

part directly observed by SAR), the rest of the spectrum, that is, the information yielded from the first guess, is deteriorated. Therefore either a more consistent procedure to augment the spectral information beyond the cut-off should be implemented or only the part of the spectrum directly mapped onto SAR images should be considered for assimilation purposes, that is the swell components longer than about $225 \mathrm{~m}$ obtained from the partitioning of the directional spectra. The latter option will reduce enormously the amount of partitions available for assimilation since, from the present data, only about $20 \%$ of the wave systems are longer than $225 \mathrm{~m}$. Nevertheless swell corrections can have a lasting impact on the forecast specially considering the directional and spectral information yielded from SAR retrievals.

\section{ACKNOWLEDGMENTS}

Violante-Carvalho has been supported by Conselho Nacional de Desenvolvimento Científico e Tecnológico $(\mathrm{CNPq})$ and also acknowledges the support of the European COST714 Action who sponsored the period that he spent as a Visiting Researcher working with Dr Susanne Lehner at the German Space Agency (DLR) in Oberpfaffenhofen, Germany. PETROBRAS, Petróleo Brasileiro S/A is acknowledged for making available the buoy data.

\section{RESUMO}

A única maneira, até o presente momento, de se medir espectros direcionais de onda com cobertura global e de forma contínua é através da utilização do Radar de Abertura Sintética (SAR da sigla em inglês) transportados em 

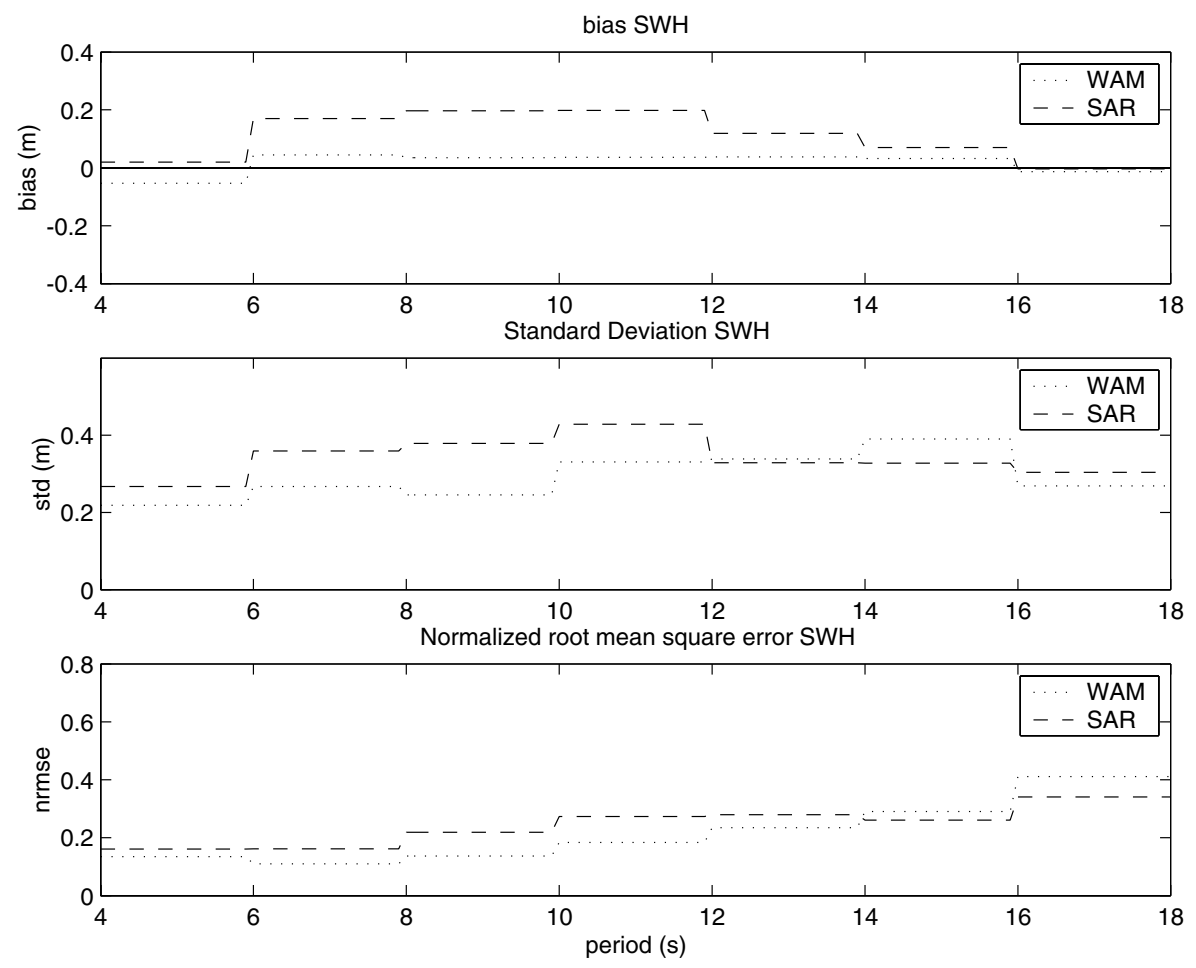

Fig. 5 - Statistics of SWH retrieved by the MPI scheme and estimated by the WAM model compared with buoy measurements over frequency bands using (2).

satélites. Milhões de imagetes SAR adquiridas com o sensor chaveado em seu modo onda (SAR Wave Mode SWM) foram e ainda estão sendo obtidas desde o lançamento no início dos anos 90 do Primeiro Satélite Europeu de Sensoriamento (ERS-1) e de seus sucessores ERS-2 e ENVISAT, o que vem criando enormes possibilidades especialmente em termos de assimilação de dados em modelos de previsão de ondas. O objetivo principal da assimilação de dados é melhorar o prognóstico inserindo as medições disponíveis no processamento do modelo de maneira que as diferenças entre as medições e as estimativas sejam reduzidas. Contudo existem limitações na recuperação dos espectros obtidos de imagens SAR devido ao alto grau de não-linearidade no mecanismo de mapeamento. No presente trabalho, um ano de medições utilizando uma bóia fundeada em águas profundas é empregado com o objetivo de investigar a adequação do esquema do Instituto Max-Planck (MPI) em recuperar a altura significativa de onda extraída das imagens SAR. O desempenho do esquema MPI, quando consideradas somente as componentes de onda com períodos inferiores a 12 segundos, é inferior ao modelo de ondas WAM utilizado como estimativa inicial para o próprio esquema, ou seja, deteriorando a estimativa inicial. Porém para períodos maiores que 12 segundos, correspondendo à parte do espectro diretamente medida pelo SAR, o desempenho do esquema MPI é tão satisfatório quanto o do modelo WAM.

Palavras-chave: Ondas geradas pelo vento, Radar de Abertura Sintética (ERS-SAR), Algoritmo do MaxPlanck Institut, Bacia de Campos, modelo de ondas WAM, medições obtidas por bóia heave-pitch-roll.

\section{REFERENCES}

BAUER E AND HeImbaCH P. 1999. Annual validation of significant wave heights of ERS-1 Synthetic Aperture Radar wave mode spectra using TOPEX/Poseidon and ERS-1 altimeter data. J Geophys Res 104: $13,345-13,357$. 
Breivik LA, Reistad M, Schyberg H, Sunde J, Krogstad HE And Johnsen H. 1998. Assimilation of ERS SAR wave spectra in an operational wave model. J Geophys Res 103: 7887-7900.

Dunlap EM, Olsen RB, Wilson L, Margerie SD AND LALBEHARRY R. 1998. The effect of assimilating ERS-1 fast delivery wave data into the north atlantic WAM model. J Geophys Res 103: 79017915.

GÜNTHER H, HASSELMANN S AND JANSSEN P. 1992. The WAModel cycle 4 (revised version). Technical report, Deutsches Klimarechenzentrum (DKRZ), Hamburg, Germany. Technical Report 4.

Hasselmann K AND Hasselmann S. 1991. On the nonlinear mapping of an ocean wave spectrum into a Synthetic Aperture Radar image spectrum and its inversion. J Geophys Res 96: 10,713-10,729.

Hasselmann K, Raney RK, Plant WJ, Alpers W, SCHUChMAN RA, LYZENGA DR, RUFENACH CL AND TUCKER MJ. 1985. Theory of Synthetic Aperture Radar ocean imaging: A MARSEN view. J Geophys Res 90: 4659-4686.

HASSELMANN K, LiONELlo P AND HASSElmanN S. 1997. An optimal interpolation scheme for the assimilation of spectral wave data. J Geophys Res 102: $15,823-15,836$.

Hasselmann S, BRÜning C, Hasselmann K AND HEIMBACH P. 1996. An improved algorithm for the retrieval of ocean wave spectra from Synthetic Aperture Radar image spectra. J Geophys Res 101: 16,615-16,629.

HeimbaCh P, HasselmanN S AND HasselmanN K. 1998. Statistical analysis and intercomparison of WAM model data with global ERS-1 SAR wave mode spectral retrievals over 3 years. J Geophys Res 103: 7931-7977.

Komen GJ, Cavaleri L, Donelan MA, HasselMANn K, Hasselmann S AND JANSSEN PAEM. 1994. Dynamics and Modelling of Ocean Waves. Cambridge University Press, Great Britain, 532 p.
Krogstag He, SAmset O AND Vachon PW. 1994. Generalizations of the non-linear ocean-SAR transform and a simplified SAR inversion algorithm. Atmosphere-Ocean 32: 61-82.

LiONELlo P, GÜNTHER H AND JANSSEN P. 1995. A sequential assimilation scheme applied to global wave analysis and prediction. Journal of Marine Systems 6: 87-107.

Mastenbroek C and de Valk CF. 2000. A semiparametric algorithm to retrieve ocean wave spectra from Synthetic Aperture Radar. J Geophys Res 105: 3497-3516.

Violante-CARVAlHo N AND Robinson IS. 2004. On the retrieval of two dimensional directional wave spectra from spaceborne Synthetic Aperture Radar (SAR) images. Scientia Marina 68: 317-330.

VIOLANTE-CARVALHO N, OCAMPO-TORRES FJ AND ROBINSON IS. 2004. Buoy observations of the influence of swell on wind waves in the open ocean. Applied Ocean Research 26: 49-60.

VIOLANTE-CARVALHO N, ROBINSON IS AND SCHULZ-STELLENFLETH J. 2005. Assessment of ERS Synthetic Aperture Radar wave spectra retrieved from the MPI scheme through intercomparisons of one year of directional buoy measurements. J Geophys Res 110, C07019, doi:10.1029/2004JC002382.

Voorrips AC, MaKin VK AND Hasselmann S. 1997. Assimilation of wave spectra from pitch-androll buoys in a north sea wave model. J Geophys Res 102: 5829-5489.

Voorrips AC, Mastenbroek C and Hansen B. 2001. Validation of two algorithms to retrieve ocean wave spectra from ERS Synthetic Aperture Radar. J Geophys Res 106: 16,825-16,840.

WAMDI GRouP. 1988. The WAM model $-\mathrm{a}$ third generation ocean wave prediction model. Journal of Physical Oceanography 18: 1775-1810. 